\title{
Momentum budget of the atmospheric boundary layer over the Greenland ice sheet and its surrounding seas
}

\author{
J. H. van Angelen, ${ }^{1}$ M. R. van den Broeke, ${ }^{1}$ and W. J. van de Berg ${ }^{1}$ \\ Received 13 December 2010; revised 7 March 2011; accepted 10 March 2011; published 18 May 2011.
}

[1] The atmospheric circulation patterns over the Greenland ice sheet and its surrounding seas are studied by explicitly calculating the momentum budget components, using data of a high-resolution regional atmospheric climate model. In winter (DJF), the katabatic pressure gradient force (PGF) dominates the momentum budget of the atmospheric boundary layer (ABL) over the ice sheet. Over the western slopes of the ice sheet, the large-scale PGF acts in the same direction as the katabatic PGF, resulting in a strong southerly jet of up to $12 \mathrm{~m} \mathrm{~s}^{-1}$. In winter, the accumulation of cold air over the sea ice along the northeast coast leads to a thermally induced northerly flow. This circulation facilitates southward sea ice transport in this area and is enhanced by the large-scale circulation. Along the west coast, a similar west-east temperature gradient also forces a northerly flow. In the summer months, sea ice is absent, and thermal wind forcing is largely reduced over the ocean.

Summer insolation also reduces katabatic forcing; the large-scale forcing dominates the ABL momentum budget over the ice sheet. Heating of the ABL over the snow-free tundra induces thermal contrasts with the ice sheet and ocean, forcing barrier winds in the coastal regions. Throughout the year, strong surface layer winds along the southeast coast of Greenland are forced by the large-scale PGF.

Citation: van Angelen, J. H., M. R. van den Broeke, and W. J. van de Berg (2011), Momentum budget of the atmospheric boundary layer over the Greenland ice sheet and its surrounding seas, J. Geophys. Res., 116, D10101, doi:10.1029/2010JD015485

\section{Introduction}

[2] Regional atmospheric circulations are very important for the climate and mass balance of ice sheets and fringing ice shelves. Local winds determine the occurrence, size and shape of polynyas and the rate of sea ice and deep water formation. Through katabatic and thermal wind forcing, wind and temperature are strongly coupled in the mostly stably stratified surface layer (SL) over the ice sheets, modifying the free atmospheric signal when it is transferred to the surface of the ice sheet. It is therefore important to assess in detail the momentum and heat budgets of the near-surface atmosphere over the ice sheets [van de Berg et al., 2008].

[3] The high shortwave reflectivity (albedo) of the ice/ snow surface in combination with the high longwave emissivity create a surface based temperature inversion, which is most pronounced in wintertime. The resultant negatively buoyant air drives the katabatic wind, which is so characteristic for sloping, ice covered surfaces. Ball [1956] and Mahrt [1982] provided a theoretical framework for the momentum budget of katabatic (gravity) flows. Since then, several field campaigns [van den Broeke et al., 1994; Heinemann, 1999; Steffen and Box, 2001a, 2001b] and modeling studies

\footnotetext{
${ }^{1}$ Institute for Marine and Atmospheric Research Utrecht, Utrecht University, Utrecht, Netherlands.

Copyright 2011 by the American Geophysical Union. 0148-0227/11/2010JD015485
}

[Bromwich et al., 1996; Heinemann and Klein, 2002; Ettema et al., 2010b] have been performed to study the katabatic wind regime over Greenland.

[4] With a height of up to $3200 \mathrm{~m}$ and located just north of the NH Atlantic storm track, the Greenland ice sheet (GrIS) has a strong influence on the atmospheric circulation in the North Atlantic region [Scorer, 1988; Petersen et al., 2004]. Owing to its size, the GrIS creates its own regional climate; beside katabatic winds, several other interesting atmospheric circulation patterns are present in the vicinity of Greenland. The atmospheric circulations along the southeastern and southern coasts have been extensively studied during the Greenland Flow Distortion experiment [Renfrew et al., 2008; Petersen et al., 2009; Renfrew et al., 2009]. High wind speed events, known as tip jets, occur south of Cape Farewell [Doyle and Shapiro, 1999; Moore and Renfrew, 2005; Vage et al., 2009]. The topography along the east coast induces convergence of the katabatic winds leading to the strong Piteraq winds [Klein and Heinemann, 2002]. van den Broeke and Gallée [1996] observed and simulated barrier winds over the western margins of the GrIS.

[5] In this study we calculate, for the first time explicitly in space and time, the components of the momentum budget of the lower atmosphere to provide a theoretical framework for the atmospheric circulation over and around the GrIS. For this we use a well evaluated 51 year run of the high resolution regional climate model RACMO2.1/GR. Section 2 briefly describes the model, the various components in the momentum budget and the data analysis applied to calculate 


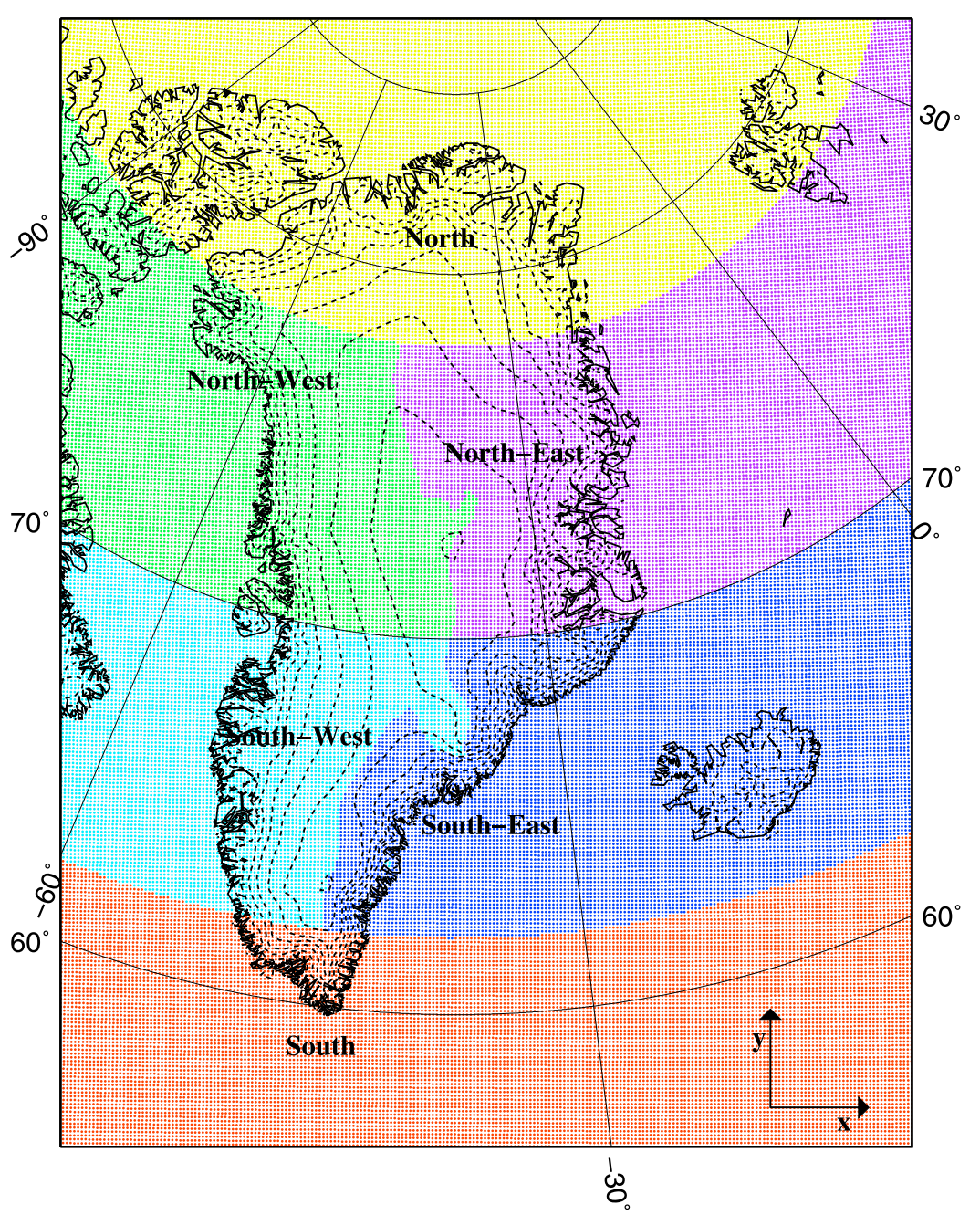

Figure 1. Definition of different areas for analysis, north (N), northeast (NE), southeast (SE), south (S), southwest (SW), and northwest (NW). Also shown are the $\mathrm{x}, \mathrm{y}$ coordinates used in this work.

these components. Section 3 presents results of the wintertime momentum budget and associated temperature and wind fields, with special focus on a cross section through northern Greenland, while section 4 presents results for the summer months. Conclusions are given in section 5.

\section{Methods}

\subsection{Model and Evaluation}

[6] We use data of the regional atmospheric climate model RACMO2.1/GR for the period 1958-2008 [Van Meijgaard et al., 2008]. RACMO2 is hosted by the KNMI (Royal Netherlands Meteorological Institute) and based on the ECMWF physics package cycle 23r4 [White, 2004], which is implemented in the numerical weather prediction model HIRLAM 5.0.6 [Unden et al., 2002]. Several adjustments have been made to make the model suitable for polar climates [Ettema et al., 2010a]. RACMO2.1/GR is a hydrostatic model with 40 sigma levels in the vertical and a horizontal grid spacing of $11 \mathrm{~km}$. Model output from this and preceding versions has been successfully used for mass balance and atmospheric boundary layer studies in Antarctica [van den
Broeke et al., 2002; Reijmer et al., 2004; van de Berg et al., 2006], and Greenland [Ettema et al., 2009; van den Broeke et al., 2009]. The model is forced at the lateral boundaries by ECMWF reanalysis (ERA-40) data every 6 hours. From August 2002 onward, operational data of the ECMWF are used. The area where the model evolves freely covers Greenland and the surrounding oceans, including Iceland and Svalbard (Figure 1). The quality of RACMO2.1/GR output (temperature, wind, moisture and surface energy balance) has been extensively evaluated by Ettema et al. [2010a] and it is shown that the model is capable of realistically resembling the (katabatic) wind regime in the Greenland area.

[7] It is obvious that a model with a grid of $11 \mathrm{~km}$ is not capable of solving small-scale processes like glacier winds, small-scale circulations in the fjord areas and the occurrence of multiple stratified layers under very stable conditions. Such processes occur on small spatial scales, but also on small time scales (hours to days). In this study we focus on the climatology of the atmospheric circulation and the previously discussed small-scale phenomena are of weak influence on the 45 year averages of the momentum budget components analyzed in this study. 


\subsection{Momentum Budget}

[8] An important component in the momentum budget of the Greenland atmospheric boundary layer (ABL) is the katabatic pressure gradient force (PGF). We use a standard $\mathrm{x}-\mathrm{y}$ coordinate system and concentrate on the momentum budget in the $\mathrm{x}$ direction, because the Greenland slopes are mostly oriented in this direction (Figure 1). The approximate momentum balance in the $\mathrm{x}$ direction, with surface slope $\alpha, U$ and $V$ the wind velocity components in the $\mathrm{x}$ and $\mathrm{y}$ directions, respectively, and $\theta_{0}$ the background potential temperature, is as follows:

$$
\begin{aligned}
\frac{\partial U}{\partial t}= & -\overbrace{U \frac{\partial U}{\partial x}-V \frac{\partial U}{\partial y}}^{\text {HADV }}-W \frac{\partial U}{\partial z}+\frac{g}{\theta_{0}} \frac{\partial \hat{\theta}}{\partial x}+f V-f V_{L S C} \\
& -\frac{\partial A D V}{\text { VADV }} \frac{\text { TH }}{\partial z}+\frac{g}{\theta_{0}} \Delta_{\theta} \sin \alpha,
\end{aligned}
$$

with $\Delta_{\theta}$ the temperature perturbation:

$$
\Delta_{\theta}(z)=\theta(z)-\theta_{0}(z),
$$

and $\hat{\theta}$ the vertically integrated temperature perturbation of the temperature deficit layer (TDL), in which $|\Delta \theta|>0$ :

$$
\hat{\theta}(z)=\int_{z}^{h_{f}} \Delta_{\theta}(z) d z
$$

where $h_{f}$ is chosen well above the TDL top. The advantage of this method is that the interface between the stable boundary layer and the free troposphere does not have to be precisely defined.

[9] The components of the momentum balance can be divided into active and passive forces. The latter are only present if atmospheric motion exists; these are the horizontal (HADV) and vertical advection (VADV), the Coriolis force (COR) and friction (FDIV). The active forces are the thermal wind (THW), katabatic (KAT) and large-scale (LSC) pressure gradient forces. KAT represents the downslope PGF resulting from a negative temperature perturbation over sloping terrain. THW is driven by horizontal variations in $\hat{\theta}$. It must be noted that these definitions for KAT and THW can lead to strong opposing forces over steep slopes if the top of the TDL is horizontal [van den Broeke and van Lipzig, 2003]. This is the situation along the east coast of Greenland, where the rough topography is engulfed in cold air; over a topographic disturbance $\hat{\theta}$ increases rapidly in the downslope direction, leading to an upslope THW forcing; on the other hand $\Delta_{\theta}$ generates a strong downslope KAT forcing. If the TDL top is horizontal these two effects exactly cancel.

[10] By calculating the different forcing components in the momentum budget explicitly, a decoupling between the free atmosphere and the ABL may also be made. THW and KAT drive flows in the ABL, whereas LSC describes flows forced by the large-scale atmospheric circulation.

\subsection{Data Analysis}

[11] In this study, a 45 year model climatology (19632007) of the ABL momentum budget for winter (DJF) and summer (JJA) is presented. To analyze the differences in wind patterns and climate over and around the GrIS, the model domain is subdivided into six regions (Figure 1). The boundary between east and west follows the ridge of the ice sheet. The distance to the coast is also used as parameter: bins of $25 \mathrm{~km}$ distance intervals are generally used, but in the coastal regions where the topography is steep and gradients in climate variables large, $10 \mathrm{~km}$ distance bins are used.

[12] To determine the large-scale wind components, it is assumed that $U_{L S C}$ and $V_{L S C}$ are in thermal wind balance with the background potential temperature $\theta_{0}$ [van den Broeke et al., 2002]:

$$
\begin{aligned}
& \frac{\partial U_{L S C}}{\partial \ln p}=+\frac{R_{d}}{f}\left(\frac{p}{p_{0}}\right)^{R_{d} / c_{p}} \frac{\partial \theta_{0}}{\partial y}, \\
& \frac{\partial V_{L S C}}{\partial \ln p}=-\frac{R_{d}}{f}\left(\frac{p}{p_{0}}\right)^{R_{d} / c_{p}} \frac{\partial \theta_{0}}{\partial x} .
\end{aligned}
$$

$\theta_{0}$ is found by linearly extrapolating the free tropospheric potential temperature to the surface with respect to pressure. For this procedure, we use 5 vertical model layers, located in the free troposphere. Furthermore a constant lapse rate $\left(\gamma_{\theta}\right)$ for the potential temperature in the free troposphere is assumed. This assumption is realistic since a maximum root-mean-square difference of $0.2 \mathrm{~K}$ between the five interpolated and real potential temperature values is found for a single grid point. We get:

$$
\theta_{0}(p)=\theta_{0}\left(p_{0}\right)+\gamma_{\theta} p
$$

The final results are not sensitive to the interpolation method used. Interpolation with respect to height instead of pressure is also tested, leading to qualitatively the same results. The number of model levels used for interpolation was also tested and likewise did not greatly affect the results.

[13] Figure 2a shows vertical profiles of the (background) potential temperature averaged over NE Greenland for the 200-225 km inland distance bin (red area in Figure 5). This result serves as example here and will be discussed more extensively in section 3.3. At the surface, the magnitude of $\Delta_{\theta}$ reaches a maximum and is as large as $16 \mathrm{~K}$. Figure $2 \mathrm{~b}$ displays wind profiles and the associated large-scale winds, Figure $2 \mathrm{c}$ the vertical profiles of the different components in the momentum budget. Due to the strong negative surface temperature perturbation, the katabatic forcing (KAT) dominates in the lowest $500 \mathrm{~m}$ of the atmosphere, resulting in a wind speed maximum 100-200 $\mathrm{m}$ above the surface. In this example the katabatic PGF dominates the momentum budget in the TDL, and is mainly balanced by surface friction (FDIV, which is parameterized by the numerical model). The largescale pressure gradient force (LSC) becomes small near the surface, because the large-scale wind is mainly in the $\mathrm{x}$ direction $(U)$ in this area. THW is a small opposing force. The FDIV profile is according to what we expect: highest values close to the surface and a changing sign at the height of the wind speed maximum. The momentum budget is closed by the residual component (RES), which represents horizontal and vertical advection of momentum and model diffusion of momentum. Advection is generally small on the spatial and time scales used in this study. Direct calculation of the horizontal and vertical advection components from model output (not shown) confirms these small values. Model diffusion of 

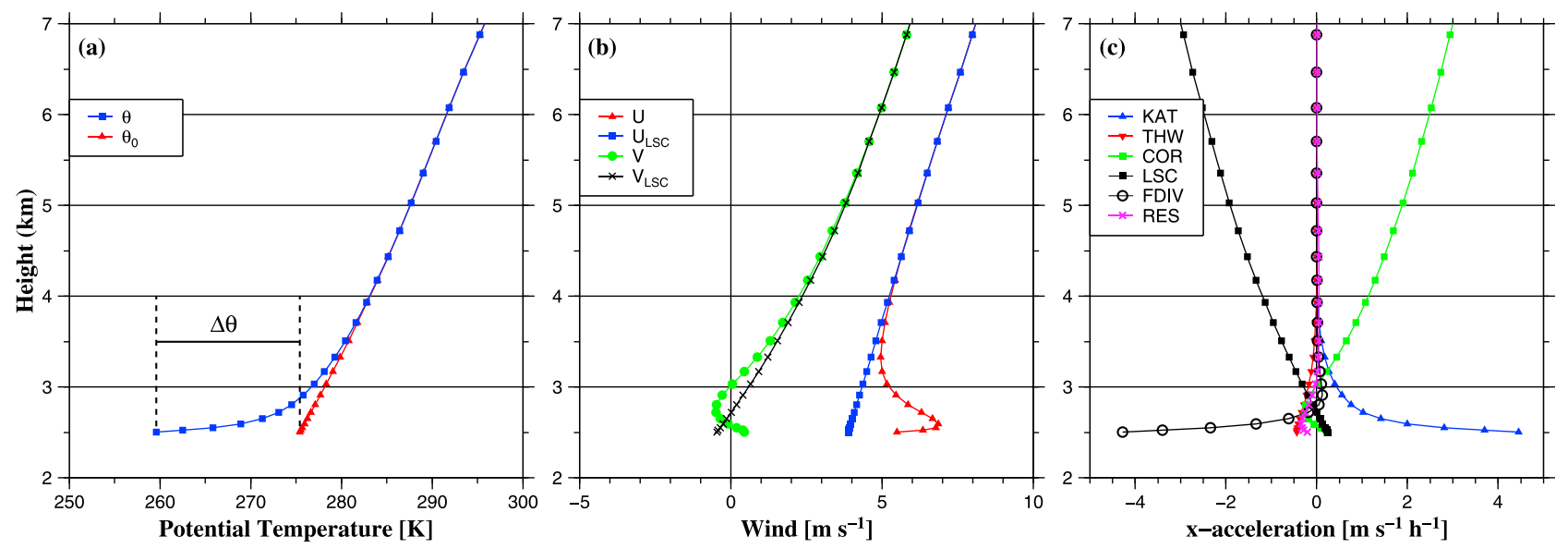

Figure 2. Average 1962-2007 (DJF) vertical profiles for the 200-225 km inland bin in the NE (red area in Figure 5): (a) potential temperature $(\theta)$ and background potential temperature $\left(\theta_{0}\right)$, (b) (large-scale) wind components, and (c) the momentum budget components. Local grid point surface elevation is $2.5 \mathrm{~km}$.

momentum is generally also small, except for the steep coastal regions, where strong gradients result in more model diffusion (see section 3.3).

\section{Results: Winter}

\subsection{Pressure, Wind, and Temperature}

[14] The $500 \mathrm{hPa}$ height contours show a southwesterly large-scale flow over the GrIS in wintertime (Figure 3a). A pressure ridge is found over the ice sheet at $500 \mathrm{hPa}$ as a result of the vertical compression of the column of air moving over the elevated ice sheet interior, resulting in more southerly flow over the western part of the ice sheet, and more westerly flow over the eastern part. The surface pressure distribution over the ocean is dominated by the Icelandic Low, and results in northerly and easterly flow near the surface. The change from southwesterly flow at $500 \mathrm{hPa}$ to northwesterly flow near the surface underlines the strong baroclinicity in this region. Also visible in the surface pressure distribution is the effect of cold air pooling, increasing the surface pressure over eastern Canada and along the north and east coasts of Greenland. Over the ice sheet, near-surface winds are highly constant in direction, and strongest over the western and northeastern ice sheet (Figure 3b). Along the east and west coasts of Greenland, persistent regional northerly flows are visible. Although high wind speeds, associated with the so-called "tip jet," often occur south of Cape Farewell, they do not show up in the average vector mean wind field, because the directional constancy of the tip jet is low [Moore, 2003].

[15] Over the GrIS, radiative cooling is strongest in winter, resulting in a large temperature deficit (Figure 3c). The average surface magnitude of $\Delta_{\theta}$ over the GrIS increases from $8 \mathrm{~K}$ in the south to values of up to $20 \mathrm{~K}$ in the NE. This local maximum is due to low cloud cover in this region, resulting in highly negative values of $L W_{\text {net }}$ [Ettema et al., $2010 \mathrm{~b}$. A strong temperature deficit of typically $6-12 \mathrm{~K}$ is also found over the sea ice covered ocean, where the atmosphere is isolated from the ocean and the surface is flat, so cold air can accumulate. Tundra areas also show large temperature deficits, for example the west coast between $65^{\circ} \mathrm{N}$ and $68^{\circ} \mathrm{N}$ and the east coast just north of $70^{\circ} \mathrm{N}$. In these flat areas, no sustained katabatic wind can develop, and strong surface based inversions develop over the snow covered tundra. Figure $3 \mathrm{~d}$ shows the average vertically integrated temperature perturbation $(\hat{\theta}$, units $1000 \mathrm{~K} \mathrm{~m})$ in winter. Surprisingly, small $|\hat{\theta}|$ values are found over the ice sheet, including areas where $\left|\Delta_{\theta}\right|$ at the surface is large. The reason is that the katabatic winds transport air radially away from the ice sheet interior, inducing mass divergence and subsidence. This keeps the TDL shallow and limits $|\hat{\theta}|$ [van den Broeke et al., 2002]. Highest magnitudes of $|\hat{\theta}|$ are found over the sea ice covered ocean along the $\mathrm{N}$ and $\mathrm{NE}$ coasts. Cold air from the ice sheet accumulates over the flat surface of the sea ice, resulting in a deep TDL and hence large $|\hat{\theta}|$. A gradual decrease in $|\hat{\theta}|$ is found in the offshore direction along the NE coast toward the sea ice-free ocean. Over the GrIS, the highest magnitudes of $|\hat{\theta}|$ are found in the NE as a result of strong temperature deficits in combination with a concave surface, limiting subsidence. Furthermore, an increase in $|\hat{\theta}|$ is present in the downslope direction over the entire ice sheet, associated with a deepening of the TDL toward the ice sheet margins.

\subsection{Momentum Budget}

[16] Figure 4a shows the magnitude and the associated geostrophic wind field of the wintertime katabatic forcing (KAT) at the first model level ( $\sim \mathrm{m}$ above the surface). Small values prevail over the relatively flat interior, rapidly increasing toward the coast. The strongest katabatic forcing is found in the NE, where values locally exceed $20 \mathrm{~m} \mathrm{~s}^{-1} \mathrm{~h}^{-1}$. This is the location with the largest temperature deficits in combination with steep slopes, in agreement with [Steffen and Box, 2001], who reported the strongest near-surface winds to occur in the NE.

[17] The strength and associated geostrophic wind field of the thermal forcing (THW) are displayed in Figure $4 \mathrm{~b}$. Gradients in $\hat{\theta}$ drive THW, therefore THW peaks in the orographically rough coastal regions, where, as explained earlier, KAT and THW become large but opposite in sign, and thus cancel. Interesting to note is that, due to the well-defined gradients in $|\hat{\theta}|$ over the northern Atlantic Ocean, THW forces 

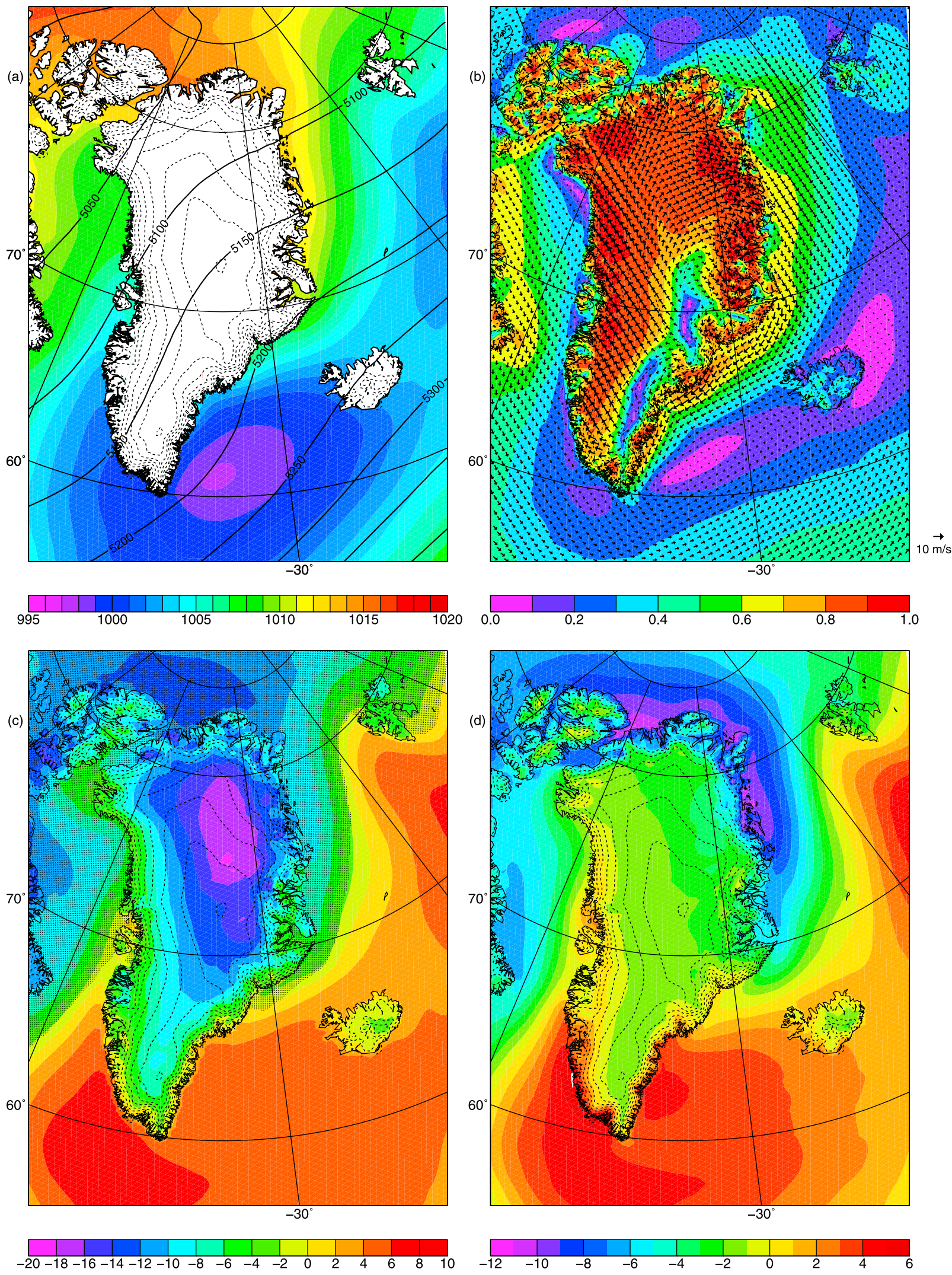

Figure 3. Averaged wintertime (DJF). (a) Sea level pressure (hPa) (colors), $500 \mathrm{hPa}$ height (m) (contours). (b) Wintertime $10 \mathrm{~m}$ winds $\left(\mathrm{m} \mathrm{s}^{-1}\right)$ and directional constancy, arrows every nine grid points. (c) Surface temperature perturbation $(\mathrm{K})$. Dotted area represents ocean with more than $50 \%$ sea ice concentration. (d) Vertically integrated potential temperature perturbation $\left(10^{3} \mathrm{~K} \mathrm{~m}\right)$. Dashed contours are $400 \mathrm{~m}$ surface elevation intervals. 

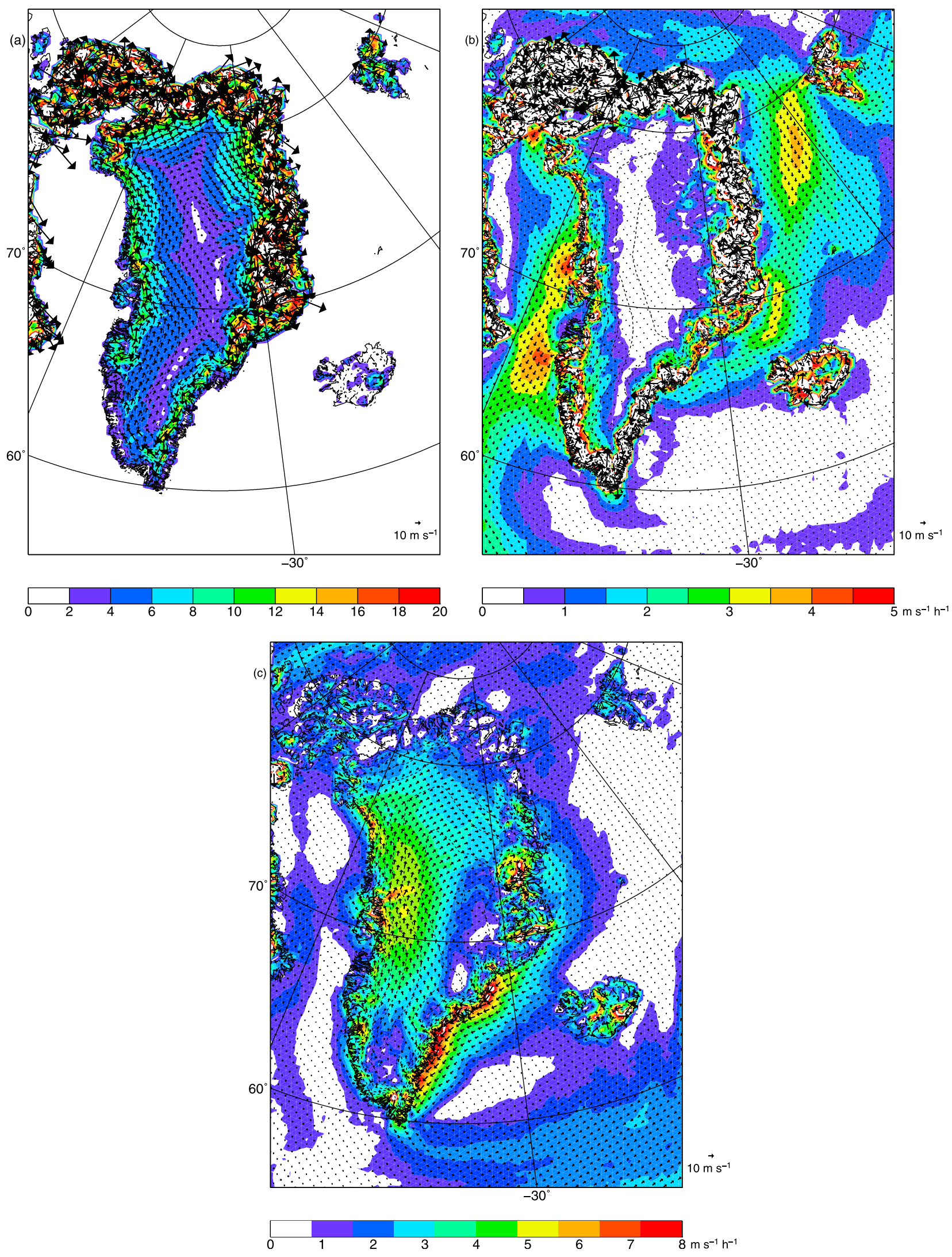

Figure 4. Spatial distribution of winter averaged magnitude of (a) KAT, (b) THW, and (c) LSC for the lowest model layer $(\sim 7 \mathrm{~m})$. Arrows indicate the associated geostrophic winds. Note the different scales. 


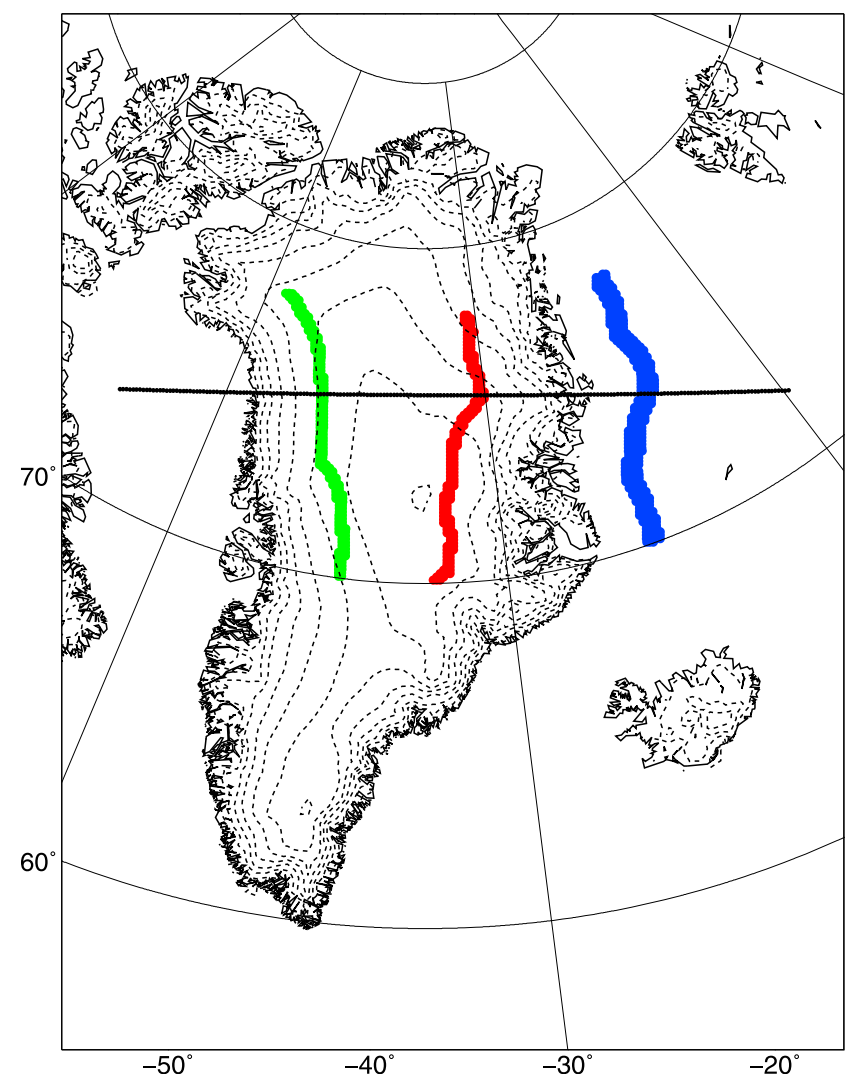

Figure 5. Locations of the transect through northern Greenland and the three areas for which winter average vertical profiles are shown.

very persistent southward flows along the east as well as along the west coast of Greenland. On the east coast, the accumulation of cold air above the sea ice covered ocean (for sea ice cover; see Figure $3 \mathrm{c}$ ) results in a negative $|\hat{\theta}|$ gradient, directed away from the coast. The associated THW forces a persistent southward geostrophic flow that facilitates the export of Arctic sea ice through Fram Strait, which is the main discharge of sea ice for the Arctic Ocean [Kwok et al., 2004]. Along the west coast of Greenland, the gradient in $|\hat{\theta}|$ is also in the west-east direction (Figure 3d). We conclude that sea ice is more attached to eastern than western coastlines in the Northern Hemisphere, because (1) cold continental air is available for sea ice growth and (2) the resulting offshore directed pressure gradient force results in a northerly flow, resulting in an Ekman transport toward the coast. Due to this asymmetric distribution of sea ice, more cold air can accumulate along the western coasts, maintaining THW and the associated southward geostrophic flow.

[18] The third active term in the momentum budget is the large-scale pressure gradient force (LSC). Figure 4c shows the magnitude and the equivalent geostrophic wind field of LSC in the surface layer. Over the ice sheet, the largest values (over $5 \mathrm{~m} \mathrm{~s}^{-1} \mathrm{~h}^{-1}$ ) are found over the western half, where the large-scale wind follows the height contours. In this area, LSC acts in the same direction as KAT (4), resulting in a strong and persistent southerly jet. Over the ocean along the southeast coast, LSC dominates the momentum budget, with values up to $8 \mathrm{~m} \mathrm{~s}^{-1} \mathrm{~h}^{-1}$. It thus appears that the associated persistent along-shore winds are not barrier winds, since
THW is small. Rather, these winds are predominantly forced by the large-scale pressure gradient, partly a result of the strong baroclinicity in this area and the vicinity of the Icelandic Low.

\subsection{Northern Transect}

[19] In this section we discuss horizontal and vertical profiles of the momentum budget and associated vertical wind and temperature distributions for a transect in north Greenland. The location of the cross section is shown in Figure 5. Potential temperature and wind speed cross sections are displayed in Figure 6a. Three well-defined boundary layer jets characterize the near-surface atmospheric circulation; two jets over both flanks of the GrIS and one over the ocean along the east coast. Average vertical profiles for the $150-175 \mathrm{~km}$ inland bin of temperature, (large-scale) winds and momentum budget components, in the NW (green area in Figure 5), are shown in Figure 7. In the free troposphere, the momentum budget reflects a simple geostrophic balance between COR and LSC (Figure 7c) with winds from the southwest. At a height of approximately $750 \mathrm{~m}$ above the surface, $\theta, U$ and $V$ start to deviate from their background values (Figures $7 \mathrm{a}$ and $7 \mathrm{~b}$ ). Below this level the katabatic forcing becomes significant. At the surface, the temperature deficit $\left(\left|\Delta_{\theta}\right|\right)$ is $\sim 10 \mathrm{~K}$, leading to a katabatic forcing of $-5 \mathrm{~m}$ $\mathrm{s}^{-1} \mathrm{~h}^{-1}$. This makes KAT the dominant forcing in the surface layer, but it is interesting to note that the large-scale forcing (LSC) is of similar magnitude and acts in the same direction. This results in a strong and persistent southerly low level jet with a wind maximum in excess of $10 \mathrm{~m} \mathrm{~s}^{-1}$. This jet is only recently identified and named the "Greenland Plateau Jet" (G. Moore, personal communication). Here we demonstrate that the jet is a result of a combination of equally important KAT and LSC forcing, comparable to strong winds found in the escarpment region of East Antarctica [van den Broeke and van Lipzig, 2003]. The difference between the large-scale and actual wind at the height of the wind speed maximum is approximately $3 \mathrm{~m} \mathrm{~s}^{-1}$.

[20] Figure 2 showed vertical profiles for the $200-225 \mathrm{~km}$ inland bin in the NE sector (red area in Figure 5). At the surface, $\left|\Delta_{\theta}\right|$ becomes as large as $15 \mathrm{~K}$, and the TDL is more than $1 \mathrm{~km}$ deep. Upper air winds are again from the southwest, however close to the surface LSC in the $\mathrm{x}$ direction is small in this area, because the large-scale flow is mainly oriented in the zonal direction. As a result the katabatic forcing dominates the momentum budget in the $\mathrm{x}$ direction and the wind profile is typically katabatic, with a sharp wind speed maximum close to the surface $\left(7 \mathrm{~m} \mathrm{~s}^{-1}\right)$. Due to surface friction and the downslope large-scale flow, the wind has a significant component in the downslope (U) direction, whereas on the west side of the ice sheet the jet is directed more along the height contours (Figure $3 b$ ).

[21] Figure 8 shows wintertime vertical profiles above the (sea ice covered) ocean between 100 and $150 \mathrm{~km}$ offshore in the NE sector (blue area in Figure 5). The temperature profiles show a thick layer of cold air, which has accumulated over the flat, sea ice covered ocean. As a result, the TDL is more than $2 \mathrm{~km}$ deep, much deeper than over the ice sheet. Because of the pronounced gradient in $|\hat{\theta}|$, THW is very significant in the boundary layer momentum budget (Figure 8c), with a forcing of $2 \mathrm{~m} \mathrm{~s}^{-1} \mathrm{~h}^{-1}$ at the surface. LSC has a similar magnitude and is also acting in the $\mathrm{E}-\mathrm{W}$ direction. As a result, 

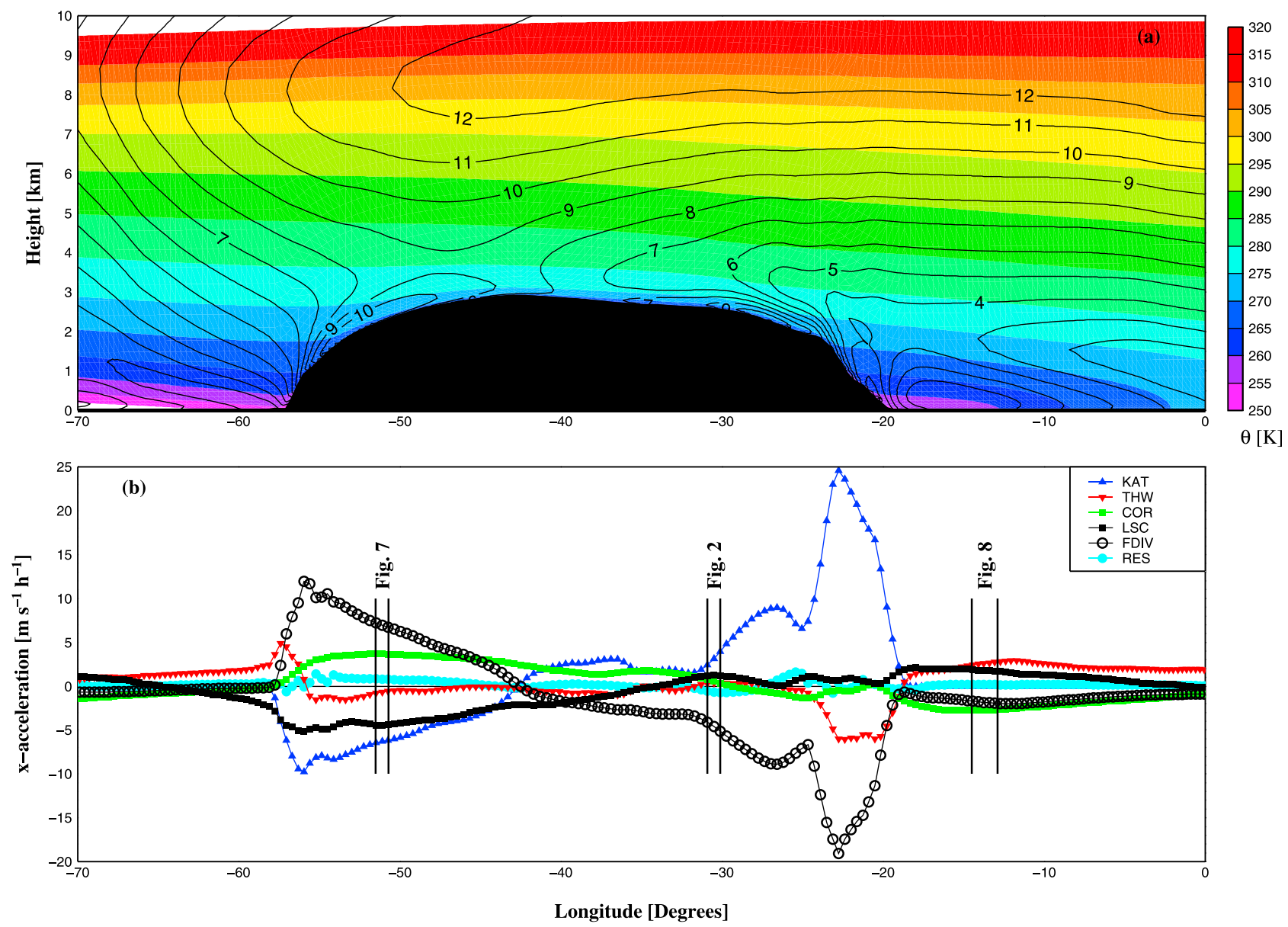

Figure 6. Transect through north Greenland for the winter months (see Figure 5): (a) potential temperature and wind speed and (b) momentum budget components in the lowest model layer ( 7 m). Vertical lines indicate positions of profiles presented in Figures 2, 7, and 8.

a persistent northerly flow is present throughout the boundary layer, with a wind speed maximum of up to $6 \mathrm{~m} \mathrm{~s}^{-1}$, and a difference between real and large-scale wind of $3 \mathrm{~m} \mathrm{~s}^{-1}$.

[22] The momentum budget along the transect at the lowest model layer (Figure 6b), together with the vertical profiles just discussed, can be used to explain the wind distribution in Figure 6a. Over the ice sheet, katabatic forcing (KAT) is the dominant component of the near-surface momentum budget. Although the magnitude of KAT is largest in the steep coastal regions, wind speeds do not necessarily peak there.
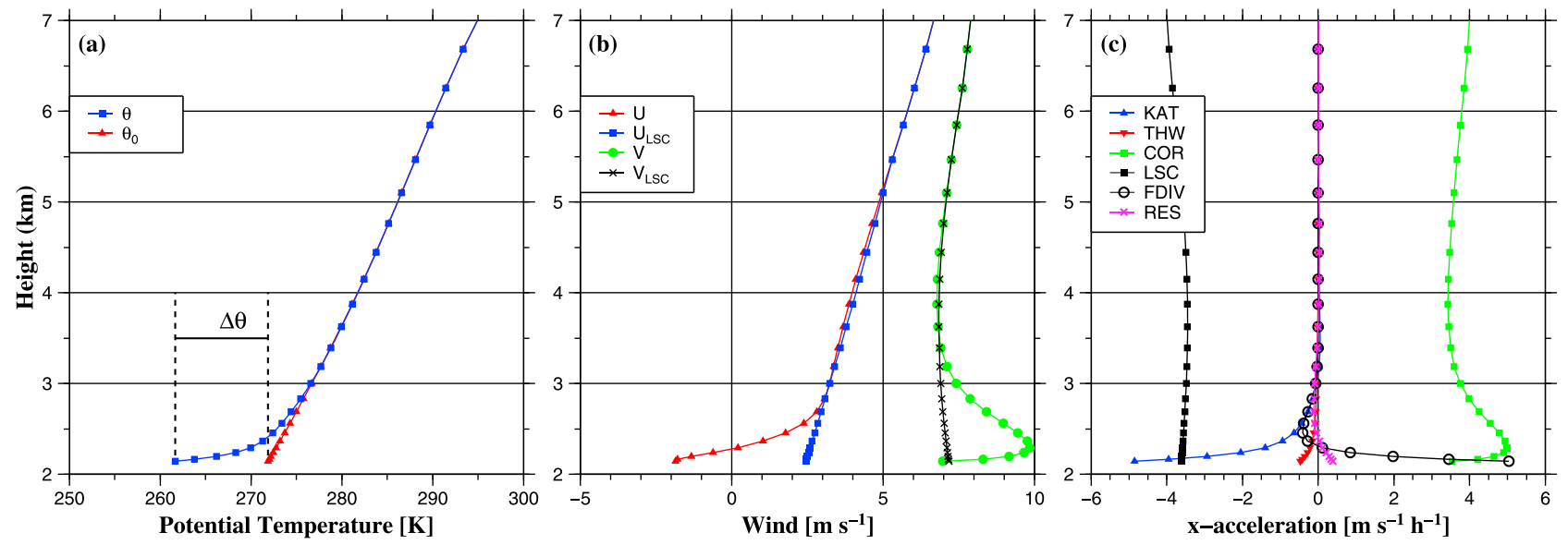

Figure 7. Average 1962-2007 (DJF) vertical profiles for the 150-175 km inland bin in the NW (green area in Figure 5): (a) potential $(\theta)$ and background potential temperature $\left(\theta_{0}\right)$, (b) (large-scale) wind components, and (c) the momentum budget components. Local grid point surface elevation is $2.2 \mathrm{~km}$. 

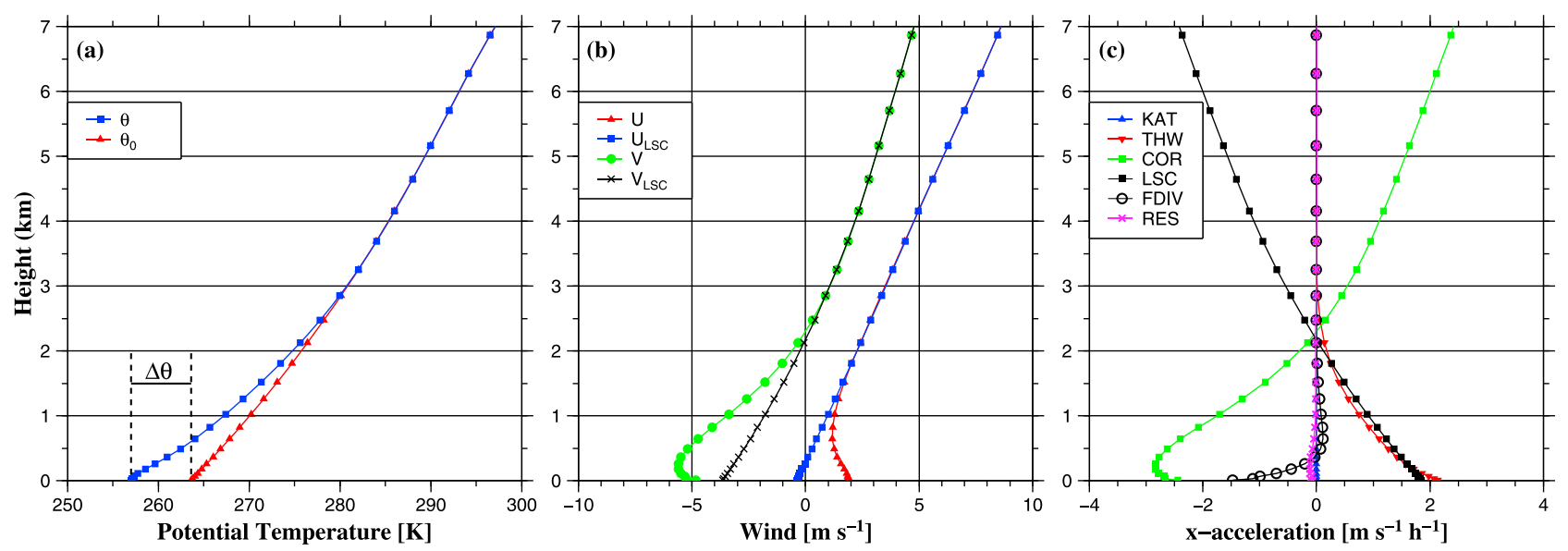

Figure 8. Average 1962-2007 (DJF) vertical profiles for the 100-150 km offshore bin in the NE (blue area in Figure 5): (a) potential $(\theta)$ and background potential temperature $\left(\theta_{0}\right)$, (b) (large-scale) wind components, and (c) the momentum budget components.

Especially on the east coast, THW is an important opposing force. The large-scale pressure gradient force (LSC) in the $\mathrm{x}$ direction is important over the western ice sheet but rather small on the east side; this is reflected in wind speed maxima that occur at a greater height above the surface than over the eastern ice sheet. To both sides of the ice sheet, colder air is present to the west, and the magnitude of THW peaks in these areas (Figure 6b). Along the east coast, LSC is enhancing THW, explaining the southward jet over the sea ice covered ocean (Figure $8 \mathrm{~b}$ ). This jet reaches up to $2 \mathrm{~km}$ into the atmosphere, and is as deep as the layer of cold air. Along the northern transect the residual component (RES) is quite small (Figure 6b), which indicates the successful separation of the components in the momentum budget and underlines that horizontal and vertical advection and model diffusion is small on the time scales used in this study.

\section{Results: Summer}

\subsection{Pressure, Wind, and Temperature}

[23] In the summer months (June, July, August) the $500 \mathrm{hPa}$ height contours (Figure 9a) show a much weaker and more westerly upper air flow over and around the Greenland ice sheet. As in winter, the pressure ridge over the GrIS is also present in summer. At the surface, the Icelandic Low is also less deep. The near surface winds (Figure 9b) are weaker than in winter, but still have high directional constancy over the ice sheet, indicative of nonzero katabatic forcing. Due to the high albedo of the ice sheet and nocturnal cooling, a temperature deficit remains present in the summer months and reaches up to 6-8 $\mathrm{K}$ in the NE (Figure 9c). In ice-free regions, a weakly positive value of $\Delta_{\theta}$ indicates convection over the snow-free tundra. Although sea ice is only present along the far NE coast, there is still a strong temperature deficit $(6 \mathrm{~K})$ over the coastal waters, which indicates the presence of warm air being advected over and cooled by cold water, deriving from melting sea ice, advection of cold arctic waters from the north and runoff from the ice sheet. The positive values of $\Delta_{\theta}$ that were found in winter over the Atlantic Ocean south of Greenland are not present in summer. This indicates that the ocean is colder than the atmosphere, resulting in a stable boundary layer. For $\hat{\theta}$ (Figure 9d) the most pronounced difference compared to winter is the absence of the pronounced $\mathrm{E}-\mathrm{W}$ gradients along the east and west coasts. Furthermore, values over the ice sheet are smaller, reflecting weaker radiative cooling.

\subsection{Momentum Budget}

[24] Over the ice sheet a weaker katabatic forcing is found in summer compared to winter (Figure 10a). For example, values around $2 \mathrm{~m} \mathrm{~s}^{-1} \mathrm{~h}^{-1}$ are found over the western slopes, compared to $10 \mathrm{~m} \mathrm{~s}^{-1} \mathrm{~h}^{-1}$ in winter. Spatial patterns of KAT-forced geostrophic winds are similar: a clockwise atmospheric circulation with increasing magnitude toward the coast. In the coastal regions, THW (Figure 10b) again represents an opposing force to KAT. Over the ocean, THW is small at the surface; sea ice, the main source of radiative cooling in winter, is not present in summer, so that the atmosphere is no longer insulated from the ocean. As a result, THW only forces rather weak regional atmospheric circulations over the ocean. In a small band around the ice sheet, nonzero THW forcing can be ascribed to heating of the tundra and relatively colder air over the ocean (sea breeze effect). The resulting PGF is directed toward the coast, driving a counterclockwise circulation. Although weaker than in winter, LSC (Figure 10c) is now relatively more important in the momentum budget, with patterns comparable to winter: a clockwise atmospheric circulation is found as a result of the high pressure over the ice sheet due to the radiative cooling of the free troposphere. Over the ocean, the strongest forcing by LSC (up to $5 \mathrm{~m} \mathrm{~s}^{-1} \mathrm{~h}^{-1}$ ) is again found along the SE coast.

\subsection{Northern Transect}

[25] Figure 11a displays potential temperature and wind speed for the northern cross section (Figure 5) in the summer months. Figure 12 shows vertical profiles for the $150-175 \mathrm{~km}$ inland bin in the NW sector (green area in Figure 5). Over the GrIS the jets over the east and west flank are still present in summer, but weaker, with maximum wind speeds of $7 \mathrm{~m} \mathrm{~s}^{-1}$. On the westside in summer, LSC is now the dominant forcing (Figures $11 \mathrm{~b}$ and $12 \mathrm{~b}$ ). The reason is that the TDL is less developed in summer, and $\mid \Delta_{\theta} I$ at the surface is less than $3 \mathrm{~K}$, 

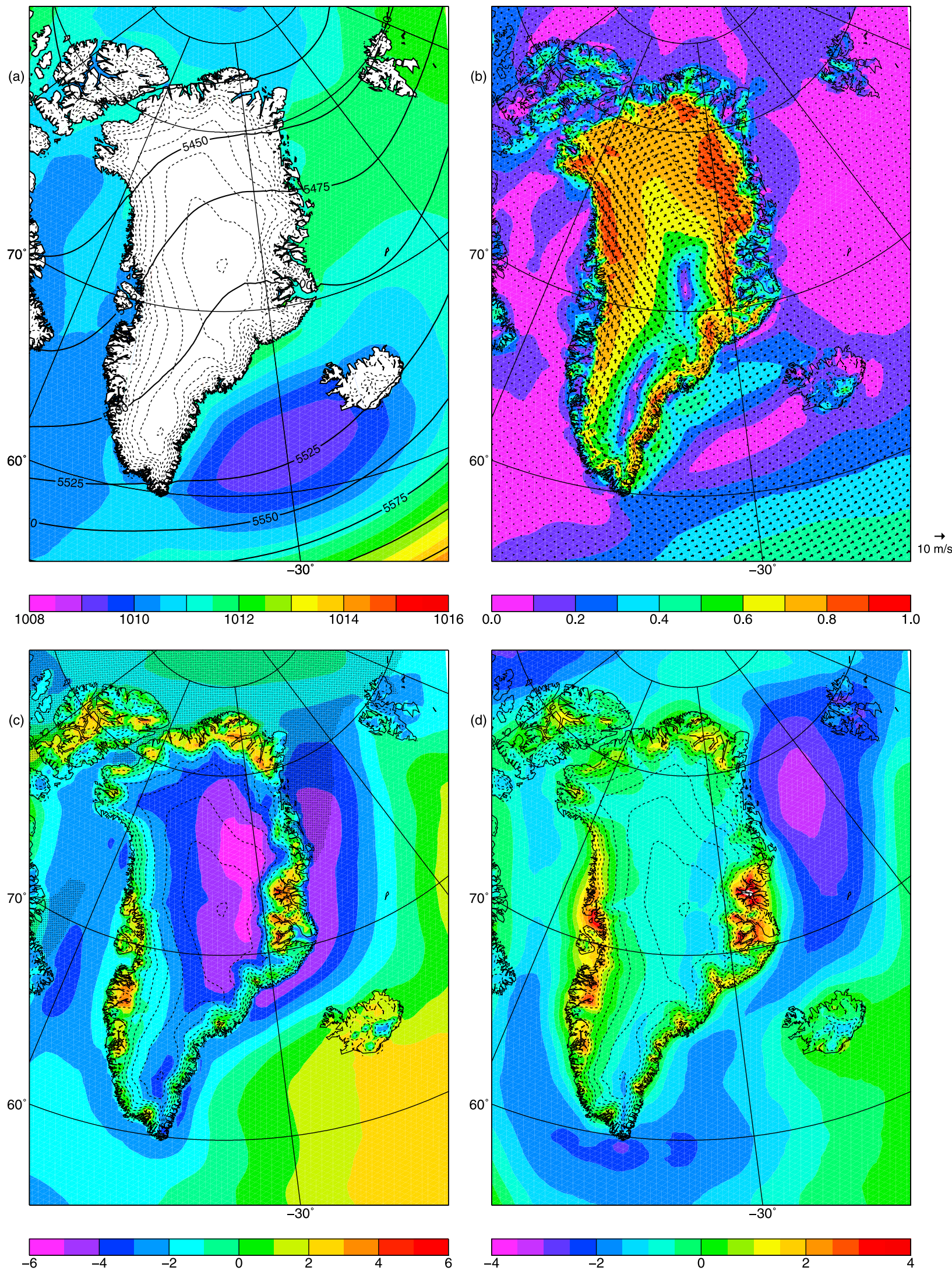

Figure 9. Averaged summertime (JJA). (a) Sea level pressure (hPa), $500 \mathrm{hPa}$ height (m). (b) Summertime $10 \mathrm{~m}$ winds $\left(\mathrm{m} \mathrm{s}^{-1}\right)$ and directional constancy, arrows every nine grid points. (c) Surface temperature perturbation (K). Dotted area represents ocean with more than $50 \%$ sea ice concentration. (d) Vertically integrated potential temperature perturbation $\left(10^{3} \mathrm{~K} \mathrm{~m}\right)$. Dashed contours are $400 \mathrm{~m}$ surface elevation intervals. 

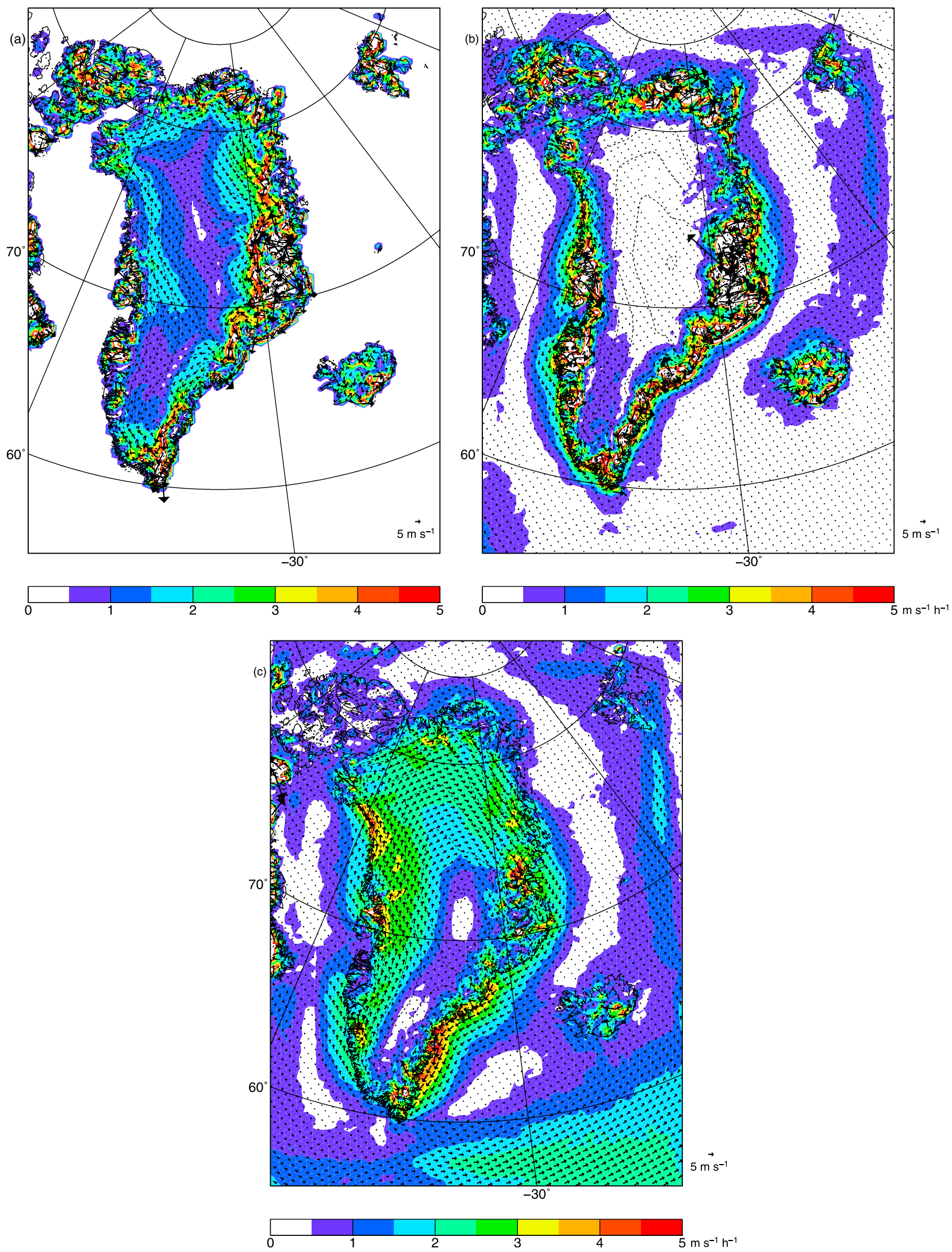

Figure 10. Spatial distribution of summer averaged magnitude of (a) KAT, (b) THW, and (c) LSC for the lowest model layer $(\sim 7 \mathrm{~m})$. Arrows indicate the associated geostrophic winds. 

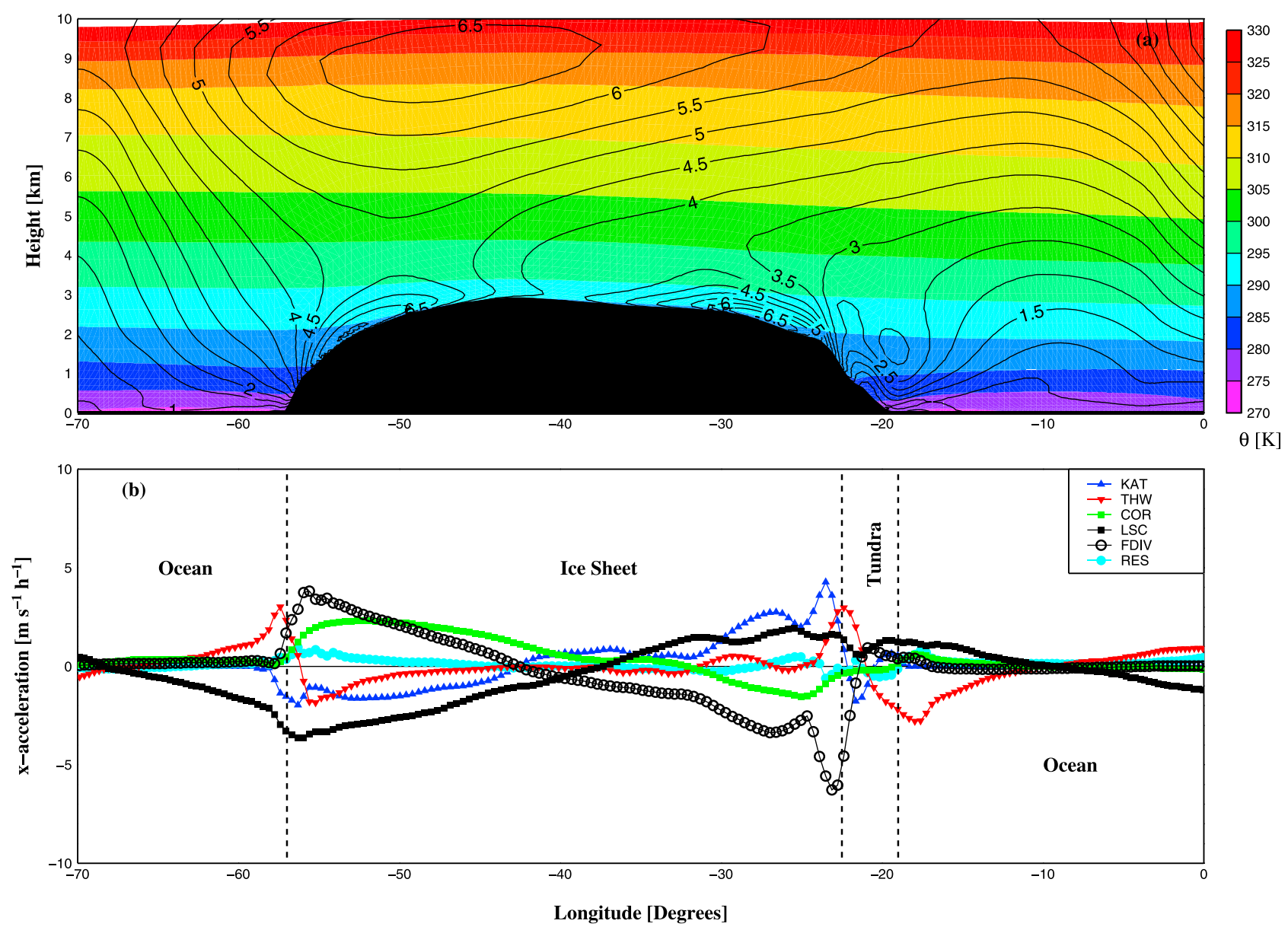

Figure 11. Transect through north Greenland for the summer months (see Figure 5): (a) potential temperature and wind speed and (b) momentum budget components in the lowest model layer $(\sim 7 \mathrm{~m})$.

resulting in relatively small magnitude of $\operatorname{KAT}\left(\sim 1 \mathrm{~m} \mathrm{~s}^{-1} \mathrm{~h}^{-1}\right)$. Otherwise, the wind profiles look rather similar to winter, with upper air winds from the southwest and the katabatic maximum in the TDL of $5.5 \mathrm{~m} \mathrm{~s}^{-1}$. The same qualitative results hold for the east side (not shown).
[26] Over the ocean (Figure 13) the layer of cold air is more shallow in summer, with a depth of less than $1 \mathrm{~km}$. A THW signal is however still present in the momentum budget, but it is now directed toward the coast. Since LSC works in the opposite direction, average near-surface winds are weak.
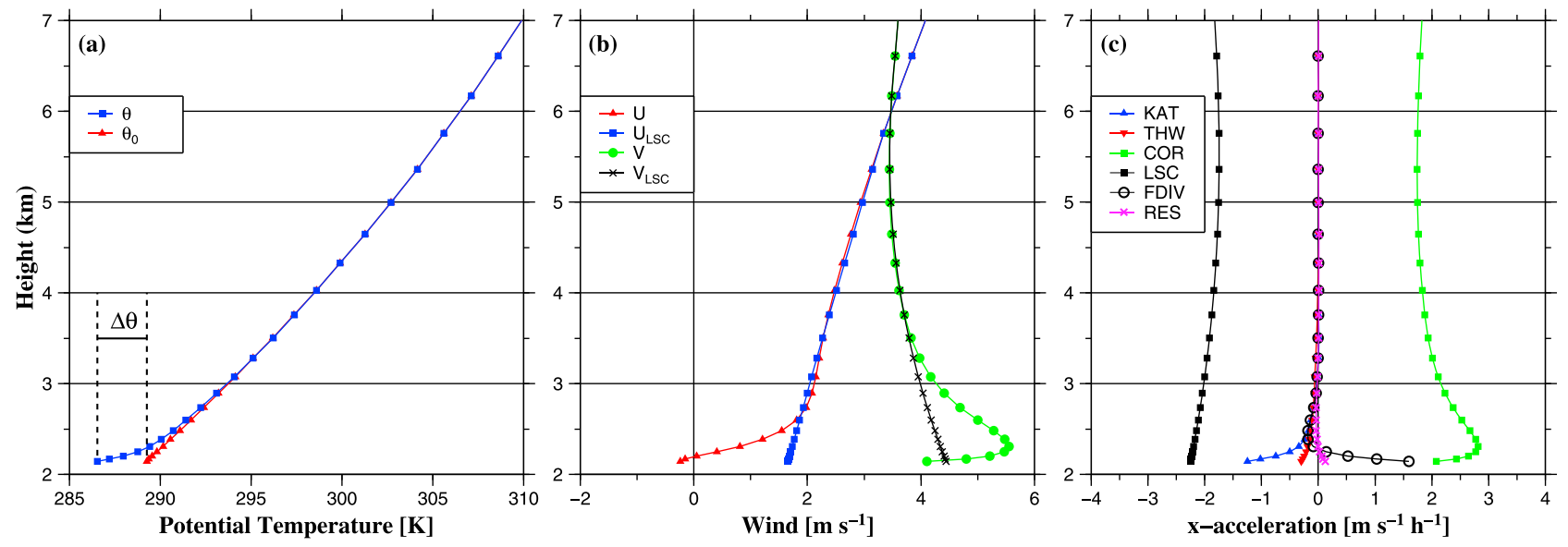

Figure 12. Average 1962-2007 (JJA) vertical profiles for the 150-175 km inland bin in the NW (green area in Figure 5): (a) potential $(\theta)$ and background potential temperature $\left(\theta_{0}\right)$, (b) (large-scale) wind components, and (c) the momentum budget components. Local grid point surface elevation is $2.2 \mathrm{~km}$. 

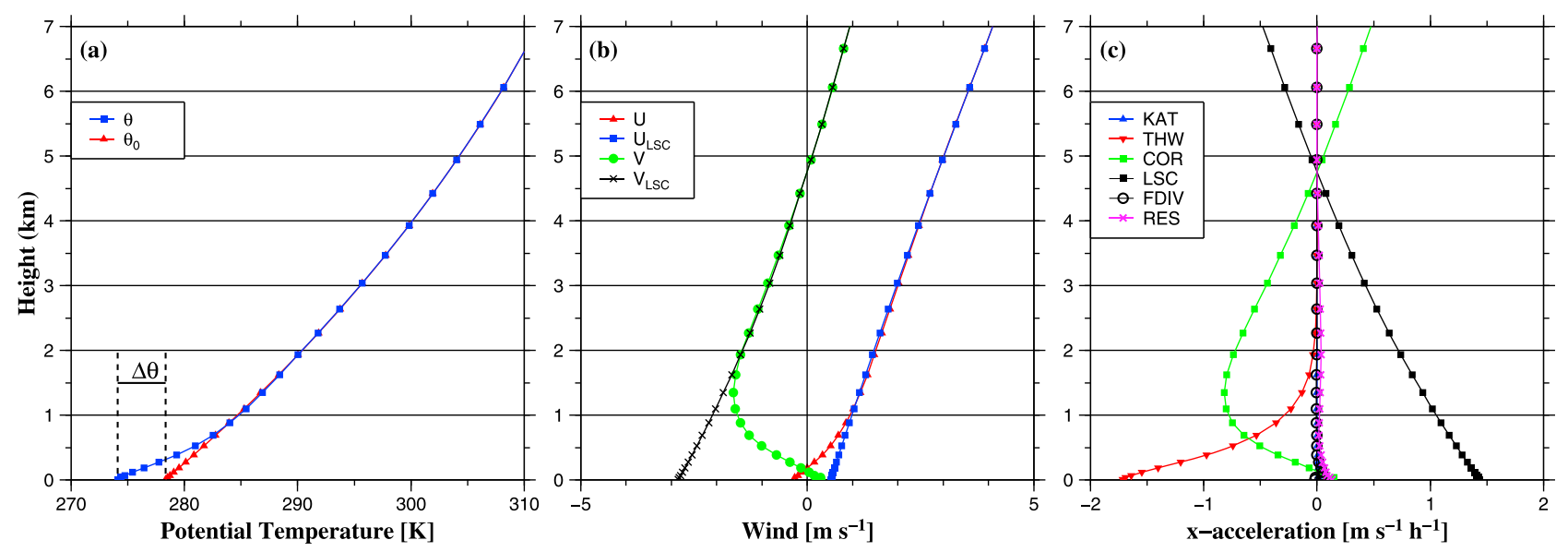

Figure 13. Average 1962-2007 (JJA) vertical profiles for the 10-50 km offshore bin in the NE: (a) potential $(\theta)$ and background potential temperature $\left(\theta_{0}\right)$, (b) (large-scale) wind components, and (c) the momentum budget components.

A closer look at the summertime momentum budget in the coastal areas show some interesting features. First of all, KAT in Figure $11 \mathrm{~b}$ changes sign on the east side, because the iceand snow-free tundra is heated, resulting in a positive $\Delta_{\theta}$. This availability of warm air also has its effect on THW. With relatively cold air above the melting ice sheet margins, warm air over the tundra and cold air again over the ocean, THW changes sign over the tundra (Figure 11b). In the northern half of Greenland, this effect is most pronounced in the east and far north, where the tundra is widest and summer insolation greatest. In the southern half of Greenland, the effect is most pronounced in the wide strip of ice-free tundra in the west. The associated barrier flow has been observed over the western tundra and melting zone during the GIMEX-90/91 field campaigns [van den Broeke and Gallée, 1996].

\section{Conclusions}

[27] We use 45 years of output from a high resolution regional atmospheric climate model to explicitly calculate the driving forces behind the atmospheric circulation over Greenland and its surrounding seas. In winter (DJF), the ice sheet surface cools the near surface air, forcing the characteristic katabatic winds. However, the large-scale circulation also plays a major role in the momentum budget over the western slopes of the ice sheet. Hence, the large-scale and katabatic pressure gradient forces drive a strong and persistent low level jet, the so-called Greenland Plateau Jet that was recently identified. Over the eastern slopes, katabatic forcing dominates. In the summer months (JJA) the large-scale forcing is weaker than in winter but more dominant in the momentum budget, because katabatic forcing has decreased even more. In spite of this, a persistent low level jet with katabatic characteristics, is still found over both the western and eastern slopes. This jet is associated with katabatic forcing through the melting ice surface and nocturnal cooling.

[28] Important atmospheric circulation patterns are also identified over the surrounding oceans. Although the wintertime upper air circulation is persistently from the southwest, surface winds over the Greenland Sea along the NE coast are mainly from the north. This circulation is driven by cold air that originates from the ice sheet and accumulates over the sea ice. The associated pressure perturbation (thermal wind) forces a southward jet along the Greenland coast, which represents an important mechanism for southward sea ice transport. Along the west coast, where colder air over the Canadian islands and warmer air over the open waters along the Greenland west coast meet, a similar thermally induced northerly flow is found. In the summer months, these thermally induced circulation patterns are not present over the ocean. Heating of the snow-free tundra, however, forces thermally driven barrier flows along the tundra/ocean and tundra/ice sheet transition zones.

[29] Finally, according to our analysis, the persistent winds along the SE coast of Greenland are of large-scale origin, both during wintertime and summertime.

\section{References}

Ball, F. (1956), The theory of strong katabatic winds, Aust. J. Phys., 9, 373-386.

Bromwich, D., Y. Du, and K. Hines (1996), Wintertime surface winds over the Greenland ice sheet, Mon. Weather Rev., 124(9), 1941-1947.

Doyle, J., and M. Shapiro (1999), Flow response to large-scale topography: The Greenland tip jet, Tellus, Ser. A, 51(5), 728-748.

Ettema, J., M. van den Broeke, E. van Meijgaard, W. van de Berg, J. Bamber, J. Box, and R. Bales (2009), Higher surface mass balance of the Greenland ice sheet revealed by high resolution climate modeling, Geophys. Res. Lett, 36, 1958-2003.

Ettema, J., M. van den Broeke, E. Van Meijgaard, and W. Van de Berg (2010a), Climate of the Greenland ice sheet using a high-resolution climate model, part 1: Evaluation, Cryosphere, 4, 561-602.

Ettema, J., M. van den Broeke, E. Van Meijgaard, and W. van de Berg (2010b), Climate of the Greenland ice sheet using a high-resolution climate model, part 2: Near-surface climate and energy balance, Cryosphere, 4, 603-639.

Heinemann, G. (1999), The kabeg-97 field experiment: An aircraftbased study of katabatic wind dynamics over the Greenland ice sheet, Boundary Layer Meteorol., 93(1), 75-116.

Heinemann, G., and T. Klein (2002), Modelling and observations of the katabatic flow dynamics over Greenland, Tellus, Ser. A, 54(5), 542-554.

Klein, T., and G. Heinemann (2002), Interaction of katabatic winds and mesocyclones near the eastern coast of Greenland, Meteorol. Appl., 9(4), 407-422.

Kwok, R., G. F. Cunningham, and S. S. Pang (2004), Fram Strait sea ice outflow, J. Geophys. Res., 109, C01009, doi:10.1029/2003JC001785.

Mahrt, L. (1982), Momentum balance of gravity flows, J. Atmos. Sci., 39, 2701-2711. 
Moore, G. W. K. (2003), Gale force winds over the Irminger Sea to the east of Cape Farewell, Greenland, Geophys. Res. Lett., 30(17), 1894, doi:10.1029/2003GL018012.

Moore, G., and I. Renfrew (2005), Tip jets and barrier winds: A QuikSCAT climatology of high wind speed events around Greenland, J. Clim., 18(18), 3713-3725.

Petersen, G., J. Kristjansson, and H. Olafsson (2004), Numerical simulations of Greenland's impact on the Northern Hemisphere winter circulation, Tellus, Ser. A, 56(2), 102-111.

Petersen, G., I. Renfrew, and G. Moore (2009), An overview of barrier winds off southeastern Greenland during the Greenland flow distortion experiment, Q. J. R. Meteorol. Soc., 135(645), 1950-1967.

Reijmer, C., E. Van Meijgaard, and M. Van den Broeke (2004), Numerical studies with a regional atmospheric climate model based on changes in the roughness length for momentum and heat over Antarctica, Boundary Layer Meteorol., 111(2), 313-337.

Renfrew, I., et al. (2008), The Greenland flow distortion experiment, Bull. Am. Meteorol. Soc., 89(9), 1307-1324.

Renfrew, I., G. Petersen, D. Sproson, G. Moore, H. Adiwidjaja, S. Zhang, and R. North (2009), A comparison of aircraft-based surface-layer observations over Denmark Strait and the Irminger Sea with meteorologica analyses and QuikSCAT winds, Q. J. R. Meteorol. Soc., 135(645), 2046-2066.

Scorer, R. (1988), Sunny Greenland, Q. J. R. Meteorol. Soc., 114(479), 3-29.

Steffen, K., and J. Box (2001a), Surface climatology of the Greenland ice sheet: Greenland climate network 1995-1999, J. Geophys. Res. 106(D24), 33,951.

Steffen, K., and J. Box (2001b), Surface climatology of the Greenland ice sheet: Greenland Climate Network 1995-1999, J. Geophys. Res., 106(D24), 33,951-33,964.

Unden, P., L. Rontu, H. Järvinen, P. Lynch, J. Calvo, G. Cats, J. Cuhart, and K. Eerola et al. (2002), HIRLAM-5 scientific documentation: December 2002, technical report, Swed. Meteorol. and Hydrol. Inst., Norrköpping, Sweden.

Vage, K., T. Spengler, H. Davies, and R. Pickart (2009), Multi-event analysis of the westerly Greenland tip jet based upon 45 winters in ERA-40, Q. J. R. Meteorol. Soc., 135(645), 1999-2011. van de Berg, W. J., M. R. van den Broeke, C. H. Reijmer, and E. van Meijgaard (2006), Reassessment of the Antarctic surface mass balance using calibrated output of a regional atmospheric climate model, J. Geophys. Res., 111, D11104, doi:10.1029/2005JD006495.

van de Berg, W., M. van Den Broeke, and E. van Meijgaard (2008), Spatial structures in the heat budget of the Antarctic atmospheric boundary layer, Cryosphere, 2, 1-12.

van den Broeke, M., and H. Gallée (1996), Observation and simulation of barrier winds at the western margin of the Greenland ice sheet, $Q$. J.R Meteorol. Soc., 122(534), 1365-1383.

van den Broeke, M., and N. van Lipzig (2003), Factors controlling the near-surface wind field in Antarctica, Mon. Weather Rev., 131, 733-743.

van den Broeke, M., P. Duynkerke, and J. Oerlemans (1994), The observed katabatic flow at the edge of the Greenland ice sheet during GIMEX-91, Global Planet. Change, 9(1-2), 3-15.

van den Broeke, M., N. van Lipzig, and E. van Meijgaard (2002), Momentum budget of the East Antarctic atmospheric boundary layer: Results of a regional climate model, J. Atmos. Sci., 59, 3117-3129.

van den Broeke, M., J. Bamber, J. Ettema, E. Rignot, E. Schrama, W. Van de Berg, E. Van Meijgaard, I. Velicogna, and B. Wouters (2009), Partitioning recent Greenland mass loss, Science, 326(5955), 984-986.

Van Meijgaard, E., L. van Ulft, W. van de Berg, F. Bosveld, B. van den Hurk, G. Lenderink, and A. Siebesma (2008), The KNMI regional atmospheric climate model RACMO version 2.1, Tech. Rep. 302, K. Ned. Meteorol. Inst., De Bilt, Netherlands.

White, P. W. (2004), IFS documentation: Part IV physical processes, IFS Doc. CY23r4, Eur. Cent. for Medium-Range Weather Forecasts, Reading, U. K

J. H. van Angelen, W. J. van de Berg, and M. R. van den Broeke, Institute for Marine and Atmospheric Research Utrecht, Utrecht University, Princetonplein 5, Utrecht, 3584 CC, Netherlands. (j.h.vanangelen@uu.nl) 